\title{
Análise de Gamificação no Simulador de Operações Cibernéticas (SIMOC)
}

\author{
Fernando José Brustolin ${ }^{1}$, José Eduardo Malta de Sá Brandão ${ }^{1}$ \\ fernando.brustolin@ipea.gov.br,je.brandao@ipea.gov.br \\ ${ }^{1}$ Instituto de Pesquisa Econômica Aplicada - IPEA, CEP 70.076-90o, Brasília, Brasil \\ DOI: 10.17013/risti.23.103-118
}

\begin{abstract}
Resumo: Este estudo qualitativo apresenta o caso do Simulador de Operações Cibernéticas (SIMOC) adotado pelo Exército Brasileiro no treinamento de pessoal em defesa cibernética, sob a perspectiva da gamificação. Investigou-se a ocorrência de onze elementos de jogos e de outras práticas associadas à gamificação do ensino e da instrução a fim de determinar se o caso SIMOC é um exemplo de gamificação. Foram coletadas evidências em documentos e por meio de entrevistas realizadas com membros da equipe que trabalha com o SIMOC e com alunos que participaram de treinamentos em que o simulador foi utilizado.
\end{abstract}

Palavras-chave: gamificação; segurança cibernética; jogos; espaço cibernético de treinamento; estudo de caso.

\section{Gamification Analysis in the Cyber Operations Simulator (SIMOC)}

Abstract: This qualitative study presents the case of the Cyber Operations Simulator (SIMOC) adopted by the Brazilian Army in staff training in cyber defense, under the perspective of the gamification. The occurrence of eleven elements of games and of other practices associated with the gamification of learning and instruction were investigated to determine whether the SIMOC case is an example of gamification. Evidence were collected from documents and through interviews made with the members of SIMOC work team and with students who participated in training sessions in which the simulator was used.

Keywords: gamification; cybersecurity; games; cyber range; case study.

\section{Introdução}

A gamificação é um fenômeno recente que busca motivar as pessoas e criar situações mais engajadoras a partir da utilização de elementos de jogos. O aumento da importância dos jogos na cultura contemporânea ressalta a relevância de estudos sobre seus benefícios e sobre a utilização de jogos, ou a utilização dos elementos que os compõem, para fins diversos do entretenimento em diversos campos profissionais, como administração, economia, saúde e educação. 
Este fenômeno também pode ser benéfico para a administração pública, enquanto prática das ações de organização e gestão para a consecução dos objetivos de um Estado ou de um governo, ao estimular a participação social dos cidadãos, aumentar a produtividade dos agentes públicos e ajudar a melhorar sua capacitação, contribuindo para que as pessoas desenvolvam habilidades importantes para a realização de seu trabalho.

O caso do Simulador de Operações Cibernéticas (SIMOC), utilizado pelo Exército Brasileiro para a o treinamento de pessoal em segurança cibernética, é um exemplo do uso de elementos de jogos no apoio às atividades de ensino e instrução. $\mathrm{O}$ estudo de caso apresentado nesse artigo buscou determinar se e como os elementos de jogos comumente encontrados em situações de ensino "gamificadas" ocorrem no caso SIMOC e também explorar a influência da utilização do simulador no aprendizado dos alunos.

A metodologia da pesquisa adotou o referencial teórico da investigação qualitativa, tanto na preparação da pesquisa, quanto na coleta dos dados e na análise integrada das evidências encontradas nas entrevistas e na documentação disponível.

Este artigo é uma versão estendida de um trabalho previamente apresentado pelos autores (Brustolin \& Bandrão, 2017) e traz, em sua próxima seção, as definições de segurança cibernética, jogos e gamificação. Em seguida, mostra a metodologia sobre pesquisa qualitativa e estudos de caso que serviu de referência na realização de tal estudo. Já a quarta seção, apresenta o caso SIMOC e os achados da pesquisa.

\section{Contextualização}

A utilização de jogos para o ensino proporciona aos jogadores o "desenvolvimento de capacidades como a persistência, bem como de destrezas cognitivas e motoras necessárias para obterem sucesso" (Carvalho, Araújo, \& Fonseca, 2015, p. 32). A evolução das pesquisas recentes sobre os benefícios dos jogos foi seguida, de certa maneira, pelo aumento na atenção ao estudo da gamificação das situações de ensino e instrução, como forma de se obter de melhores resultados de aprendizado.

A capacitação de suas forças militares em segurança cibernética reflete as preocupações que o Estado brasileiro tem com as crescentes ameaças cibernéticas. Os conceitos centrais a esta discussão, são apresentados a seguir.

\subsection{Segurança Cibernética}

Cibernética é uma palavra de origem grega que denomina o campo de estudo do controle e da regulação de sistemas em geral, sejam mecânicos e elétricos ou sociais e biológicos, e que foi apropriada "pela ficção científica para significar qualquer coisa associada à tecnologia dos computadores" (Salen \& Zimmerman, 2004b, p. 118). Este significado, de coisas ligadas ao campo da computação, também é mesmo dado ao termo pelos membros do Exército Brasileiro.

O Departamento de Segurança Nacional dos Estados Unidos da América (2015, tradução nossa) define segurança cibernética como sendo "a atividade ou processo, a habilidade, capacidade ou o estado de coisas por meio dos quais as informações e os sistemas de comunicação e as informações neles contidas são protegidos e/ou defendidos contra danos e uso, modificação ou exploração não autorizados" e seu foco de atuação está na 
"proteção de computadores, dispositivos móveis, tablets, redes, programas e dados de acessos ou de manipulações não autorizados".

\subsection{Jogos}

O interesse nos jogos como elemento da cultura se iniciou no final do século XVIII (Caillois, 1967), mas o estudo das relações entre jogos e a cultura só veio a se desenvolver em meados do século XX a partir do trabalho de Johan Huizinga (Salen \& Zimmerman, 2004a).

Para Avedon \& Sutton-Smith "cada pessoa define jogos à sua própria maneira - os antropólogos e especialistas em folclore, em termos de origens históricas; os militares, empresários e educadores em termos de usos; os sociólogos em termos de funções psicológicas e sociais" e, para eles, existem "provas contundentes de que o significado de jogos é, em parte, uma função das ideias daqueles que pensam a respeito deles" (Avedon \& Sutton-Smith, 1971, p. 438 apud Salen \& Zimmerman, 2004a, p. 19). Para Jane McGonigal (2011, p. 31), "o que define um jogo são as metas, as regras, o sistema de feedback e a participação voluntária”, sendo todo o resto "um esforço para consolidar e fortalecer esses quatro elementos principais".

Salen \& Zimmerman (2004a, p. 95) definem jogo como sendo "um sistema no qual os jogadores se envolvem em um conflito artificial, definido por regras, que implica um resultado quantificável”. A partir desta definição, Karl Kapp (2012) afirma que num contexto de instrução "um jogo é um sistema no qual os jogadores se envolvem em um desafio abstrato, definido por regras, interatividade e feedback, que que implica um resultado quantificável, geralmente evocando uma reação emocional” (p. 7, tradução nossa) e que os elementos presentes em sua definição - jogador, feedback, interação, desafio, regras, reação emocional, resultado quantificável - fazem surgir algo maior quando combinados do que se considerados individualmente.

\section{Tipos de Jogos}

As características inerentes a cada jogo despertam o interesse de diferentes jogadores, conforme suas preferências e predisposições pessoais. Caillois (1967, pp. 31-33) propôs que os jogos fossem agrupados em categorias que representassem a predominância do papel dos "impulsos essenciais e irredutíveis" de competição, sorte, simulacro ou vertigem, as quais chamou, respectivamente de agôn, alea, mimicry e ilinx. Kapp (2012) classifica os principais tipos de jogos como sendo de competição, de cooperação ou aqueles que permitem aos jogadores exercer sua criatividade e auto expressão.

Outros estudiosos do tema criaram sistemas para classificar os jogadores conforme seus interesses. Bartle (1996) distingue os jogadores em matadores, conquistadores, exploradores e socializadores, conforme a predominância de seus interesses intrínsecos em relação ao ambiente do jogo e aos outros jogadores. Marczewski (2013) modificou esta tipologia para torna-la mais adequada ao contexto da gamificação e a seus usuários, com uma categoria que acomoda indivíduos motivados a jogar por recompensas externas.

De fato, ao pensarmos em diferentes tipos de jogadores, estamos considerando os tipos de jogos que as pessoas gostam de jogar, ainda que, todos estes diferentes tipos de jogo aconteçam misturados de alguma maneira nos jogos ou nas iniciativas de gamificação. 
Assim, é importante que, ao se projetar jogos ou soluções gamificadas, se leve em conta quais características deverão se sobrepor às outras por terem maior apelo junto do público-alvo pretendido (Kapp, 2012).

\subsection{Gamificação}

Apesar de ter sido cunhado em 2002, o termo gamificação só veio se disseminar nesta década (Kim, 2015) e tem sido utilizado em contextos variados como instrumento para entender e influenciar comportamentos humanos que se deseja encorajar (Dale, 2014), se apresentando como "um fenômeno emergente com muitas potencialidades de aplicação em diversos campos da atividade humana” (Fardo, 2013, p. 3).

Para Deterding, Dixon, Khaled, \& Nacke (2011), a gamificação demarca um grupo de fenômenos distintos, mas que não haviam sido especificados anteriormente, e que eles definiram como sendo "o uso de elementos de projeto de jogos fora dos contextos de jogos” (p. 10, tradução nossa).

Da perspectiva do projeto de jogos, uma solução gamificada é vista como um sistema que inclui elementos de jogos, mas não é um "jogo propriamente dito"; já sob a perspectiva de quem utiliza uma solução gamificada, esta pode ser encarada e experimentada como um jogo propriamente dito, como algo que pode ser jogado, como algo divertido ou como qualquer outra coisa e é essa abertura nas interpretações possíveis que as distingue de um "jogo propriamente dito" (Deterding et al., 2011, p. 12, tradução nossa).

Outros autores têm um entendimento mais ampliado sobre o que é gamificação. Kapp (2012) considera como sendo exemplos de gamificação aqueles casos que têm um propósito diverso do simples entretenimento e define gamificação como sendo "a utilização de mecânicas e estética baseadas em jogos e do pensamento de jogo para engajar as pessoas, motivar a ação, promover o aprendizado e resolver problemas” (p. 10, tradução nossa).

Nesta definição, pensamento de jogo deve ser entendido pelo forma se encarar uma experiência cotidiana como se fosse uma atividade que possui elementos de competição, cooperação, descoberta e narrativa; engajamento significa chamar a atenção de uma pessoa e envolvê-la no processo criado; a motivação é um processo que dá direção, propósito e significado aos comportamentos e às ações; e a gamificação também promove o aprendizado, uma vez que muitos de seus elementos são técnicas de ensino e instrução (Kapp, 2012).

Para Kim (2015), a especificação e o uso dos mesmos elementos utilizados para se projetar um jogo em atividades e serviços que não são jogos, torna mais fácil distinguir esse grupo de fenômenos que constituem a gamificação. Assim, "para algo ser entendido como gamificação e não como jogo, seu objetivo deve ser resolver um problema do mundo real" (Kim, 2015, p. 14, tradução nossa).

Em decorrência do aumento da utilização de elementos de jogos em serviços na internet, houve uma proliferação das técnicas de ensino com enfoque gamificado como forma de aumentar o engajamento, a relevância e a imersão dos alunos, colaborando para a transformação do ensino em uma realidade contemporânea na qual o tempo e a atenção dos alunos são limitados e as metodologias de ensino precisam ser adaptadas a estas novas formas de aprender (Kapp, 2012; Poy-Castro, Mendaña-Cuervo, \& González, 2015). 
As diferentes definições de jogos existentes consideram elementos variados como sendo seus constituintes. Assim, esta pesquisa sobre gamificação num caso de instrução de segurança cibernética considerou aqueles elementos que Kapp (2012) coloca como sendo os mais comumente utilizados fora do contexto de jogos em situações de gamificação da instrução: abstração de conceitos e da realidade; metas; regras; conflito, competição ou cooperação; tempo; estruturas de recompensa; feedback; níveis; narrativa; curva de interesse; estética; replay ou tentar novamente. Além destes, o autor também apresenta, como algo comumente encontrado em tais situações, as práticas do monitoramento da curva de interesse dos alunos e da realização de debriefing.

\section{Metodologia}

O objetivo do trabalho foi investigar e analisar se e como os elementos de jogos mais comumente encontrados em iniciativas gamificadas de ensino ou instrução ocorrem na utilização do Simulador de Operações Cibernéticas (SIMOC). Também foram explorados os resultados obtidos com a utilização do SIMOC, a partir da perspectiva teórica da gamificação.

A utilização do SIMOC no ensino e na instrução em segurança cibernética é um caso particular, uma vez que a maior parte das iniciativas que podem ser encaradas como exemplos de gamificação nessa área são casos em que as ferramentas de simulação ou os jogos adotados não são capazes de proporcionar aos alunos o realismo e outras peculiaridades dos treinamentos.

As estratégias, ou abordagens, investigativas podem ser tanto quantitativas, quanto qualitativas ou de métodos mistos, e dão uma "direção específica" aos métodos adotados, que são as formas particulares de "coleta, análise e interpretação dos dados" adotadas em um estudo específico (Creswell, 2009, pp. 35-36, 40).

Apesar dos estudos quantitativos demonstrarem as frequências e distribuições entre as variáveis estudadas e suas correlações, eles têm dificuldade em esclarecer a orientação das correlações encontradas ou de esclarecer como é ser afetado por determinado fenômeno estudado e quais são as implicações e o significado disso num contexto cotidiano para os sujeitos envolvidos (Flick, 2007).

Por outro lado, a pesquisa qualitativa "se concentra mais no significado vinculado a alguns fenômenos ou nos processos que revelam como as pessoas lidam com eles" e seu objetivo principal é "descobrir novos aspectos na situação que está sendo estudada" (Flick, 2007, pp. 35, 23-24), como novas teorias ou lacunas no conhecimento já existente que são desenvolvidas a partir do daquilo que já existe na literatura teórica ou empírica sobre o tema em estudo (Flick, 2007).

Uma das vantagens geralmente observáveis numa estratégia qualitativa é que um pequeno número de casos e participantes são selecionados conforme sua relevância e a coleta de dados é concebida de forma mais aberta que em uma abordagem quantitativa, de modo que os participantes podem apresentar a situação em seu contexto real e com mais liberdade para determinar o que é importante para eles (Flick, 2007). Assim, os objetos em estudo determinam a escolha de um método e podem ser "representados 
em sua totalidade, dentro de seus contextos cotidianos" sem a necessidade de serem reduzidos a variáveis (Flick, 2007, p. 24).

O tipo de questão de pesquisa que se pretende responder, a extensão do controle que um pesquisador tem sobre os eventos comportamentais reais e o grau de enfoque sobre os eventos contemporâneos em oposição aos eventos totalmente históricos devem ser levados em consideração ao se optar por uma dessas maneiras (Yin, 2014). De forma complementar, Morse (1991) afirma que uma questão de pesquisa essencialmente qualitativa possui características que não estarão presentes em um problema cujo cerne seja quantitativo.

Por isso, uma abordagem qualitativa pode contribuir com o entendimento do fenômeno da gamificação sob diversos aspectos, uma vez que o tema nunca foi estudado no caso escolhido, além de ser um tópico novo que ainda não foi pesquisado exaustivamente.

Para Creswell (2009, pp. 35-41), estudo de caso é uma das estratégias de investigação qualitativa mais comumente encontradas, utilizando diversos procedimentos de coleta de dados e explorando profundamente "um programa, um evento, uma atividade, um processo ou um ou mais indivíduos" relacionados "pelo tempo e pela atividade”. Já Flick (2007, p. 135) entende que "o objetivo dos estudos de caso é a descrição exata ou a reconstrução de um caso", sendo o termo "caso" bem abrangente e podendo representar "pessoas, comunidades sociais, organizações e instituições".

Segundo Yin (2014, pp. 12-13, 17-18) este método é o preferido para o exame de eventos contemporâneos ou de um passado recente, quando, além das técnicas e fontes de evidência da pesquisa histórica, também é possível a observação direta dos eventos em estudo ou a entrevista das pessoas neles envolvidas, compreendendo "um método abrangente[... que] cobre a lógica do projeto, as técnicas de coleta de dados e as abordagens específicas à análise de dados" onde, como nas situações do mundo real, nem sempre é possível distinguir claramente o fenômeno do contexto. Os diversos métodos e procedimentos utilizados para a preparação da pesquisa, a coleta de dados e a análise são descritos a seguir.

\subsection{Preparação}

Segundo Yin (2014), a adequada seleção do caso a ser estudado é considerada uma atividade preparatória e o mais importante na preparação para este tipo de pesquisa é a elaboração de um protocolo para guiar a coleta de dados.

O caso SIMOC se mostrou revelador, pois, além da solução estudada ser o único espaço de treinamento cibernético, ou cyber range, em operação na América Latina, os estudos anteriores relacionando cyber range à gamificação não tiverem enfoque em responder como os elementos de jogos se manifestam na solução e como os alunos treinados são impactados por seu uso. O protocolo elaborado para o estudo de caso foi baseado nas sugestões de Yin (2014) e serviu como subsídio na elaboração de uma carta de apresentação, assim como indicado por Creswell (2009), para obtenção de acesso para a condução do estudo.

\subsection{Coleta de Dados}

Além da possibilidade de utilizar fontes contemporâneas de evidência, "um importante ponto forte da coleta de dados do estudo de caso é a oportunidade de usar diferentes 
fontes de evidência”, permitindo que sejam abordadas uma maior variedade de evidências e desenvolvidas "linhas convergentes de investigação" (Yin, 2014, pp. 123-124). Para Yin (2014, p. 124) "qualquer achado ou conclusão do estudo de caso é, provavelmente, mais convincente e acurado se for baseado em diversas fontes diferentes de informação, seguindo uma convergência semelhante". A triangulação de dados acontece quando as descobertas são "apoiadas por mais do que uma única fonte de evidência”, ou seja, quando dados coletados de diferentes fontes "proporcionam [...] várias avaliações do mesmo fenômeno" e corroboram uma mesma descoberta (Yin, 2014, p. 125).

Stake (2010, pp. 138-141) também reconhece a importância da triangulação de dados como forma de "aumentar a confiança" nas evidências que devem ser interrelacionadas para a construção de um "caso integrado". O planejamento e a coleta de dados são realizados para se "obter uma evidência de boa qualidade" (Stake, 2010, p. 132) e, com essa intenção, este estudo buscou evidências através de entrevistas e da análise documental.

A equipe do SIMOC e alunos das instruções no qual ele é utilizado foram entrevistados. Considerou-se como equipe do SIMOC os profissionais com elevado conhecimento da ferramenta e que a manipulam em sua rotina de trabalho, quer seja como instrutor do Centro de Instrução em Guerra Eletrônica (CIGE) ou como participante das equipes técnicas que desenvolvem melhorias no simulador e trabalham na sustentação de sua operação.

Foram realizadas seis entrevistas com perguntas abertas, onde um protocolo orientava quais questões e tópicos deveriam ser buscados pelo pesquisador. Elas ocorreram em junho e julho de 2016, tiveram cerca de uma hora de duração e seu áudio gravado. A equipe do SIMOC foi entrevistada até a saturação das respostas, isto é, até que parassem de variar ou de trazer novas evidências relevantes ao estudo. Já os alunos entrevistados foram aqueles aos quais foi possível o acesso, ou seja, oficiais militares liberados de suas obrigações nos momentos em que o pesquisador estava no local e que concordaram em participar.

$\mathrm{Na}$ análise documental foram levantados cerca de 50 documentos entre publicações oficiais e artigos de revistas do setor de defesa ou entrevistas e notícias sobre o SIMOC veiculadas na imprensa. Destes, em pouco mais de 20 documentos foram selecionados fragmentos que puderam ser utilizados para contextualizar o estudo de caso, definir termos específicos da área militar e corroborar evidências levantadas nas entrevistas. Fragmentos são "uma história, algum texto ou outro item possivelmente digno de inclusão na pesquisa” (Stake, 2010, p. 239).

\subsection{Análise Integrada das Evidências}

A análise das evidências coletadas foi realizada a partir das questões estabelecidas no protocolo do estudo de caso, conforme recomendado por Yin (2014) e Patton (2001). A escolha pela estratégia adotada não foi algo planejado antecipadamente, pois, como Yin (2014, pp. 139-140) afirma, pode ser necessário "ir para frente ou para trás" reiteradas vezes até que uma estratégia se mostre viável, isto é, tentar avançar para as conclusões a partir das expectativas iniciais ou tentar retornar a essas expectativas após manipular os dados, uma vez que os padrões, insights ou conceitos que pareçam promissores poderão 
emergir durante essa manipulação. Assim, para cada uma das entrevistas foi produzido um caso individual que tentava responder as questões estabelecidas para o caso SIMOC e selecionar fragmentos da entrevista.

Conforme indicado por Yin (2014), a escrita do estudo de caso, ou síntese dos casos individuais já registrados, buscou triangular evidências de diferentes fontes de dados sempre que possível como forma de corroborar as descobertas e conclusões. Dessa maneira, como explica Patton (2001), a perspectiva de cada um dos participantes de um estudo de caso único acaba por dar origem a um estudo de caso que passa a integrar a análise do estudo de caso principal.

\section{O Caso SIMOC}

A análise das entrevistas e da documentação levantada sobre o SIMOC permitiu a contextualização histórica, a avaliação da presença dos elementos de jogos e a identificação de outros elementos, conforme descrito a seguir.

\subsection{Recuperação Histórica}

A sociedade depende cada vez mais de sistemas de informação em rede e a segurança desses sistemas passa a ser um assunto que preocupa cada vez mais os governos, as empresas e os cidadãos (Vaizey, 2015). O aumento desta dependência também afeta as Forças Armadas brasileiras, que utilizam redes de computadores para operar e interconectar seus sistemas táticos, deixando-os expostos às vulnerabilidades próprias do espaço cibernético (Gomes, 2014).

O Centro de Instrução em Guerra Eletrônica (CIGE) foi criado em 1984 para capacitar recursos humanos e desenvolver doutrina em Guerra Eletrônica. A partir de 2012 passou a oferecer o Curso de Guerra Cibernética (Brasil, 2015) e logo ficou evidente que era necessário ter um ambiente controlado para o treinamento de pessoal, levando à busca por uma solução de simulação para essa finalidade. Era necessário um espaço cibernético controlado que possibilitasse o treinamento de pessoal e que também fosse uma solução mais prática do que a configuração manual de dezenas de computadores para cada situação diferente de treinamento.

Assim, apesar de existirem diversos simuladores já desenvolvidos para o treinamento em segurança cibernética (Machado, Costa, \& Rezende, 2015, p. 1270), o Exército Brasileiro optou pelo desenvolvimento de uma nova solução, pois buscava um produto que pudesse ter seus códigos-fonte auditados e que "permitisse a criação de novos cenários [de treinamento] e pudesse ter seus cenários [já existentes] modificados pela própria equipe de instrutores do CIGE, tanto para criar variações dos exercícios quanto [para] mantê-los atualizados", sendo esta liberdade de expansão o maior diferencial em relação aos simuladores disponíveis no mercado à época.

O desenvolvimento do simulador promoveu a tecnologia nacional de defesa e sua primeira versão levou cerca de um ano para ficar pronta e envolveu mais de trinta militares, possibilitando a entrada em operação do primeiro Simulador de Operações Cibernéticas do país no ano de 2013 (Agência Brasil, 2013; Brasil, 2013). 
O Simulador de Operações Cibernéticas (SIMOC) é uma ferramenta de treinamento, um software que dá "mais dinamismo e qualidade aos treinamentos de militares" e "permite ensinar situações de ataque e defesa” cibernética (Agência Brasil, 2013). Seus cenários de treino incluem "catástrofes e comprometimentos de infraestruturas nacionais" e são "constantemente renovados", permitindo "executar ações de proteção cibernética em ambiente controlado" (Lemos, 2015). O SIMOC pode ser considerado uma solução de espaço cibernético de treinamento, ou de cyber range, apresentando diversos diferenciais quando comparado a outros simuladores.

\subsection{Elementos de Jogos}

Os elementos comumente encontrados em jogos podem ser encontrados combinados de diferentes maneiras nas situações de treinamento em segurança cibernética em que o SIMOC é utilizado no CIGE, fazendo com que elas possam ser consideradas exemplos de gamificação. É a inter-relação de vários destes elementos que faz com um jogo se torne algo engajador, uma vez que um único elemento, ou apenas dois deles, não são suficientes para fazer de um ambiente de aprendizado algo imersivo e engajador (Kapp, 2012).

\section{Narrativa}

Os cenários de todos os treinamentos são contextualizados, fazendo das narrativas um elemento importante e permitindo que os alunos reconheçam uma razão nas atividades realizadas no ambiente cibernético do simulador e que participem da história colocada conforme avancem pelas tarefas de seu treinamento. "A gente sempre tem uma situação contextualizada, a gente não está fazendo aquilo só por fazer” (Entrevistado 4). Não existem, no SIMOC, treinamentos descontextualizados, sem uma história de fundo, ainda que simples.

\section{Abstração de Conceitos e da Realidade}

A abstração de conceitos reduz a complexidade das situações, tornando mais fácil para o jogador lidar com o espaço conceitual sendo experimentado e com o desenrolar dos acontecimentos (Kapp, 2012). Os conceitos de instrução trabalhados nas atividades com o SIMOC são contextualizados através de 'situações particulares', que tornam o entendimento do problema mais fácil e definem as metas imediatas. "Se você não gerar uma situação particular, não se traz o aluno para uma realidade [...] se esse contexto é gerado, [...] ele foi colocado dentro de uma situação em que fica mais fácil" (Entrevistado 2).

\section{Metas}

Um jogo pode ter mais de uma meta e elas têm a função de introduzir objetivos, foco e resultados mensuráveis a uma experiência; as metas intermediárias conduzem a uma meta final e podem ser incrementais, devendo permitir ser alcançadas de maneiras variadas pelos jogadores (Kapp, 2012; Nicholson, 2012; Salen \& Zimmerman, 2004a). A ligação entre as metas colocadas e aquilo que os alunos precisam aprender pode criar uma experiência significativa (Nicholson, 2012). 
No SIMOC, para se atingir o objetivo de um treinamento é necessário que tarefas que possuem resultados quantificáveis sejam realizadas. Estas tarefas são apresentadas numa gradação de dificuldade, levando ao desenvolvimento de habilidades que servem de fundamentos para a realização de outras tarefas mais complexas. "Todos [os exercícios] têm objetivos. Ontem [, durante um CTF,] eram quinze exercícios, cada um deles tem a finalidade de encontrar o que a gente chama de 'flag', que é encontrar o objetivo daquela questão" (Entrevistado 3).

\section{Regras}

As regras estabelecem os limites de ação dos jogadores e devem ser aceitas para que o jogo seja possível, podendo decorrer de requisitos de instrução que se deseje enfatizar no jogo ou de um acordo tácito ou explícito entre os jogadores (Caillois, 1967; Kapp, 2012; Salen \& Zimmerman, 2004b). As regras de cada treinamento com o SIMOC (regras instrucionais) guiam o aprendizado prático do conhecimento a ser desenvolvido, conforme a situação. Elas "são totalmente flexíveis, e vão da criatividade do instrutor, do que ele quer que o aluno aprenda" (Entrevistado 1).

Os instrutores também seguem regras específicas para a criação de cenários de treinamento no SIMOC (regras constitutivas), relacionadas às limitações e à arquitetura da ferramenta. O aprendizado das regras de uso do SIMOC pelos alunos é facilitado por instrutores, ajudando-os a focar no aprendizado dos conhecimentos relativos à instrução e não no funcionamento da ferramenta.

\section{Conflito, Competição ou Cooperação}

Em um jogo, espera-se que conflito, competição e cooperação se entrelacem ao longo de seu enredo (Kapp, 2012), mas, em geral, no SIMOC estes elementos não ocorrem num mesmotreinamento. A variação de situações de conflito, competição ou cooperação ocorre ao longo do curso, em diferentes treinamentos, cada um deles, geralmente, com enfoque em uma situação específica. "Você pode montar equipes, você pode fazer treinamentos individuais e você pode montar equipes uma contra a outra” (Entrevistado 5).

\section{Tempo}

Via de regra, o tempo que os alunos têm para concluir os treinamentos no SIMOC élimitado. A restrição do tempo é a forma mais comum de se utilizar o elemento em jogos (Kapp, 2012). Outra forma comum com que este elemento é trabalhado a compressão de tempo, como forma de acelerar o curso natural dos eventos e ressaltar as relações causa-e-efeito desejadas e deixar o enredo menos cansativo. Esta forma de manipulação do tempo poderia ser mais explorada pelo SIMOC, pois são poucas as situações em que a simulação acelera os eventos para ressaltar as relações entre ações e consequências. "[...] um treinamento [dura] um período de tempo. [...] existe uma linha do tempo que pode ser usada para programar as ações que irão ocorrer em determinados momentos" (Entrevistado 2).

\section{Estruturas de Recompensa}

É preciso ter cautela com a utilização das estruturas de recompensa, pois apesar de não serem algo ruim por si próprias, os distintivos, os pontos e as recompensas não são 
os únicos componentes da gamificação. Entender como elas podem funcionar e como integra-las aos jogos é importante, mas é preciso ter em mente que elas têm um papel a desempenhar como parte integrante dos jogos e não como foco de uma iniciativa de gamificação (Kapp, 2012). Pontos e prêmios pelo desempenho durante o treinamento são as estruturas de recompensa mais utilizadas no SIMOC. Em alguns treinamentos um quadro de pontuação é exibido a todos os alunos, funcionando como um placar para estimular a competição, "como se existisse um placar [...] e os alunos veem esse placar" (Entrevistado 6).

A premiação dos “jogadores” pela pontuação conquistada ocorre em alguns treinamentos, e permite que eles troquem pontos obtidos nas tarefas já realizadas por informações que os ajudarão a atingir outros objetivos. "Você pode comprar dica, que é o mundo real. Com dinheiro se compra a informação que te permite chegar mais rápido ao objetivo" (Entrevistado 2).

\section{Feedback}

A frequência e a intensidade do feedback são vantagens que os jogos têm sobre um ambiente de ensino tradicional. O feedback pode ser apenas informativo, indicando o grau de acerto ou erro de uma resposta, ação ou atividade, ou guiar o aluno em direção ao resultado esperado sem dizer exatamente o que fazer, a não ser ter conhecimento de que a atividade que você escolheu não estava correta. Geralmente esses dois mecanismos de feedback se sobrepõem (Kapp, 2012).

A maior parte do feedback no SIMOC não ocorre de maneira automática, como num jogo, dependendo da atuação do instrutor. Entretanto, apesar de não ser imediato, o feedback do instrutor é mais intenso por ser específico para o aluno, "eu posso dar alguma coisa que conduza o raciocínio do camarada a entender" (Entrevistado 6). Além de poder ocorrer através do ambiente do SIMOC, a orientação pode ser dada pessoalmente pelo instrutor, "não precisa ser pessoalmente, ir lá e falar, [mas] também pode, [...] viu que o cara não está andando, você vai ali e dá uma orientação" (Entrevistado 5).

\section{Níveis}

Segundo Kapp (2012), jogos têm diferentes tipos de níveis: uma estrutura baseada em níveis ou missões, na qual os jogadores progridem de um nível para o próximo conforme eles se movem em direção ao final do jogo; o grau de dificuldade que o jogador escolhe quando entra no jogo pela primeira vez; e o nível de experiência e habilidades que um jogador obtém durante o jogo.

No SIMOC, é possível identificar os conceitos de níveis baseados em missões e de diferentes graus de dificuldade. Os múltiplos treinamentos e as múltiplas tarefas que existem em um mesmo treinamento cumprem a função de reduzir o escopo dos problemas que devem ser resolvidos. "Tem, situações em que você precisa resolver um problema para chegar em outros. [A dificuldade] costuma aumentar. $O$ instrutor pode, até mesmo no meio de uma simulação, mudar a dificuldade de uma simulação" (Entrevistado 5). 


\section{Estética}

A função dos elementos estéticos em um jogo é criar um ambiente imersivo para contribuir com a experiência de jogo, mas jogos educacionais e simulações costumam não dar a devida atenção a estes elementos (Kapp, 2012).

A estética da área através da qual o aluno companha os objetivos e tarefas do treinamento parece não ter sido alvo de muita atenção no SIMOC. O espaço cibernético de treinamento, entretanto, é análogo à realidade e pode ajudar na sensação de imersão, "o SIMOC é um emulador com características de simulação [...] um emulador substitui o real" (Entrevistado 2) e "sensação de que eu estou dentro de uma rede de verdade [...] o SIMOC consegue proporcionar" (Entrevistado 3).

Além disso, a integração do espaço cibernético de treinamento com o mundo físico, no ambiente do aluno, apesar de ainda pouco explorado, podem tornar os treinamentos muito atraentes. "Em alguns casos há uma sinergia entre o mundo cibernético do jogo e o mundo cinético" (Entrevistado 2), por exemplo, "o aluno consegue controlar o semáforo, consegue controlar o placar, o trenzinho, a hidrelétrica [de uma maquete]" (Entrevistado 1).

\section{Replay ou "Tentar Novamente"}

Nos jogos, função de replay ou tentar novamente dá ao jogador a permissão para falhar. Falhar com consequências mínimas encoraja o aprendizado baseado na exploração, na curiosidade e na descoberta. Jogos dão a oportunidade de explorar um conjunto de regras, de testar hipóteses e de se lembrar de quais abordagens foram bem-sucedidas e quais falharam (Kapp, 2012).

No SIMOC, exceto nas situações de avaliação, os alunos são livres para tentar quantas vezes forem necessárias para resolver suas tarefas e caso alguma ação do aluno leve o cenário que ele utiliza a tornar-se inutilizável e o impeça de prosseguir com seu treinamento, é possível ao aluno solicitar ao instrutor que determinadas partes do cenário ou, até mesmo, o cenário como um todo, sejam restaurados à sua situação inicial.

\section{Debriefing e Monitoramento da Curva de Interesse}

Apesar de o debriefing e o monitoramento da curva de interesse não serem elementos de jogos propriamente ditos, estas práticas também são comumente encontradas em iniciativas de gamificação.

No caso SIMOC, após um exercício no simulador é normal ocorrer uma sessão de "retificação de aprendizado", que podem ajudar na resolução de problemas futuros e tem sua importância reconhecida pelos alunos e instrutores: "é fundamental [...e se] mais à frente, em outros exercícios, até mesmo de outras matérias, surgia um problema semelhante àquele e graças a essa retificação a gente conseguia resolver no próximo também” (Entrevistado 3); "porque se não tiver essa retificação a gente termina o exercício, mas o objetivo que os instrutores queriam alcançar com aquilo, nem eles não vão saber e nem nós se foi plenamente alcançado, ou o que faltou" (Entrevistado 4). 
A prática de monitoramento da curva de interesse não foi observada no caso SIMOC e, apesar de existir um processo de acompanhamento contínuo dos alunos no CIGE, o interesse deles por diferentes tipos de jogo não é determinado e nem monitorado.

\subsection{Achados Adicionais}

A adoção da pesquisa qualitativa permitiu que fossem revelados aspectos não esperados sobre o caso estudado. Esse esclarecimento de como um fenômeno afeta o cotidiano daqueles envolvidos e revela tais aspectos é uma das principais características da pesquisa qualitativa. Os principais aspectos identificados no caso SIMOC foram os seguintes:

\section{Motivação}

Ainda que a motivação dos alunos para ingressar no curso pareça ser intrínseca, aqueles que passam pelo treinamento esperam algum tipo de reconhecimento por terem concluído o curso e também esperam, como recompensa extrínseca ao SIMOC, que um bom desempenho nos treinamentos contribua para sua carreira profissional. Entretanto, o aluno do Exército Brasileiro que concluiu o curso de Guerra Cibernética não ganha nenhuma distinção além de passar a figurar no Hall de Guerreiros Cibernéticos do CIGE.

Além disso, apesar da possibilidade de poder contar com uma ferramenta de simulação em sala de aula não ter sido determinante para que os alunos procurassem o curso, um deles afirmou que passaria a considerar tal fator no momento de procurar um curso futuro.

\section{Engajamento}

Tanto os instrutores, quanto os alunos entrevistados relatam uma preferência pelas atividades do curso que eram realizadas no SIMOC, que despertam maior interesse nas turmas de estudantes. Apesar disso os entrevistados não consideraram que a utilização do SIMOC foi responsável por um maior nível de participação das turmas treinadas.

Alguns entrevistados relataram problemas pontuais com a solução tecnológica desenvolvida pelo Exército Brasileiro, que acabaram por interferir momentaneamente na experiência com o simulador. Apesar disso, não foram encontradas evidências de que a utilização do SIMOC tenha causado algum efeito negativo no aprendizado.

\section{Beneficios}

O uso de elementos de jogos e simulação possibilita aos alunos do CIGE a experimentação em ambientes mais próximos da realidade, com situações que não seriam possíveis de praticar sem uma ferramenta como o SIMOC, preparando mais rapidamente o aluno para agir em situações práticas. As inovações que o SIMOC trouxe para o processo de ensino e instrução no CIGE também trouxeram benefícios para os instrutores, dando mais agilidade na preparação de cenários de treinamento e a possibilidade de reutilizar treinamentos prontos ou de reaproveitar elementos anteriores na elaboração de novos treinamentos.

\section{Conclusões}

A importância contemporânea que a segurança cibernética tem assumido pode ser percebida por meio das preocupações crescentes sobre tema que os Estados, além de 
outros agentes econômicos, vêm demonstrando. Assim, torna-se relevante estudar as possibilidades de melhoria no ensino e instrução de segurança cibernética através do uso da gamificação.

O trabalho se valeu de uma abordagem qualitativa de investigação para responder as questões de pesquisa, de como a gamificação ocorre no caso do Simulador de Operações Cibernéticas (SIMOC) e apresentar sua utilização no contexto real. O uso de uma abordagem qualitativa também propiciou a descoberta de aspectos que foram além daqueles inicialmente considerados para o estudo.

Foram encontrados todos os elementos de jogos investigados, sendo importante ressaltar que nem todos eles acontecem numa mesma situação de treinamento e que isso já é previsto pelas teorias da gamificação. Além disso, para os alunos é melhor treinar utilizando um simulador de grande porte num ambiente cibernético que permite a experimentação e dá a eles o direito de errar sem se preocupar em danificar uma infraestrutura importante. O realismo proporcionado por esse espaço cibernético de treinamento ajuda a desenvolver os alunos mais rapidamente, deixando-os mais bem preparados para a atuação imediata em atividades práticas.

\section{Referências}

Agência Brasil. (2013). Exército apresenta Simulador Nacional de Operações Cibernéticas. Obtido (26 de Maio de 2016), de: http://www.ebc.com.br/noticias/ brasil/2013/o1/exercito-apresenta-simulador-nacional-de-operacoes-ciberneticas

Avedon, E. M., \& Sutton-Smith, B. (Eds.). (1971). The Study of Games. New York: John Wiley.

Bartle, R. (1996). Hearts, Clubs, Diamonds, Spades: players who suit MUDs. Obtido (13 de Maio de 2016), de: http://mud.co.uk/richard/hcds.htm

Ministério da Defesad do Brasil. (2013). Exército apresenta Simulador Nacional de Operações Cibernéticas. Obtido (26 de Maio de 2016), de: http://www.defesa.gov. br/noticias/4212-22-01-2013-defesa-exercito-apresenta-simulador-nacional-deguerra-eletronica

Comando de Comunicações e Guerra Eletrônica do Exército, Brasil. (2015). CIGE. Obtido (26 de Maio de 2016), de: http://www.ccomgex.eb.mil.br/index.php/ centro-instrucao-guerra-eletronica

Brustolin, F. J., \& Brandão, J. (2017). Uma Análise Qualitativa do SIMOC sob a Perspectiva da Gamificação. Em Atas do $6^{\circ}$ Congresso Ibero-Americano em Investigação Qualitativa: Investigação Qualitativa na Engenharia e Tecnologia Vol. 4, pp. 93-103. Aveiro: Portugal: Ludomedia. Obtido de http://proceedings. ciaiq.org/index.php/ciaiq2017/article/view/1131

Caillois, R. (1967). Os jogos e os homens: a máscara e a vertigem. Lisboa: Edições Cotovia, 1990. 
Carvalho, A. A., Araújo, I., \& Fonseca, A. (2015). Das Preferências de Jogo à Criação do Mobile Game Konnecting: um estudo no ensino superior. RISTI - Revista Ibérica de Sistemas e Tecnologias de Informação, (16), 30-45. https://doi.org/10.17013/ risti.16.30-45

Creswell, J. W. (2009). Projeto de pesquisa: métodos qualitativo, quantitativo e misto (3. ${ }^{\mathrm{a}}$ ed.). Porto Alegre: Artmed.

Dale, S. (2014). Gamification : Making work fun, or making fun of work? Business Information Review, 31(2), 82-90. https://doi.org/10.1177/0266382114538350

Deterding, S., Dixon, D., Khaled, R., \& Nacke, L. (2011). From Game Design Elements to Gamefulness: Defining «Gamification». Em MindTrek 2011 (pp. 9-15). https://doi. org/10.1145/2181037.2181040

Estados Unidos da América. (2015). Cybersecurity 101. Obtido (19 de Agosto de 2016), de: https://niccs.us-cert.gov/awareness/cybersecurity-101

Fardo, M. L. (2013, Agosto 5). A Gamificação Aplicada em Ambientes de Aprendizagem Renote. Obtido de: http://seer.ufrgs.br/index.php/renote/article/view/41629

Flick, U. (2007). Introdução à Pesquisa Qualitativa (3. ${ }^{\mathrm{a}}$ ed.). Porto Alegre: Artmed, 2009.

Gomes, H. S. (2014). Exército brasileiro incluirá Argentina em treinamento de guerra cibernética. Obtido (29 de Junho de 2016), de: http://g1.globo.com/tecnologia/ noticia/2014/05/exercito-brasileiro-incluira-argentina-em-treinamento-deguerra-cibernetica.html

Kapp, K. M. (2012). The Gamification of Learning and Instruction: Game-based Methods and Strategies for Training and Education. Obtido de: https://books. google.com/books?hl=pt-BR\&lr=\&id=M2Rb9ZtFxccC\&pgis=1

Kim, B. (2015). Understanding Gamification. Library Technology Reports, 51(2), 1-35. Obtido de: https://www.journals.ala.org/ltr/issue/viewFile/502/252

Lemos, A. B. (2015). Brasil: forças armadas fortalecem a ciberdefesa do país. Obtido (17 de Julho de 2016), de: https://dialogo-americas.com/pt/articles/brasil-forcasarmadas-fortalecem-ciberdefesa-do-pais

Machado, A. F. A., Costa, F. A. C. R., \& Rezende, J. L. de. (2015). Use of simulation to achieve better results in cyber military training. Em MILCOM 2015 - 2015 IEEE Military Communications Conference (pp. 1270-1275). Tampa, FL, USA: IEEE. https://doi.org/10.1109/MILCOM.2015.7357620

Marczewski, A. (2013). Gamification: a simple introduction and a bit more (2. ${ }^{\mathrm{a}}$ ed.). Amazon Digital Services (autopublicação). Edição para Kindle.

McGonigal, J. (2011). A realidade em jogo. Rio de Janeiro: Bestseller. 
Morse, J. M. (1991). Approaches to qualitative-quantitative methodological triangulation. Nursing research, 4O(2),120-123.https://doi.org/10.1097/00006199-19910300000014

Nicholson, S. (2012). A User-Centered Theoretical Framework for Meaningful Gamification. Games+ Learning + Society, 1-7. https://doi.org/10.1007/978-3319-10208-5_1

Patton, M. Q. (2001). Qualitative research and evaluation methods (3. ${ }^{a}$ ed.). Thousand Oaks, California: Sage.

Poy-Castro, R., Mendaña-Cuervo, C., \& González, B. (2015). Diseño y evaluación de un juego serio para la formación de estudiantes universitarios en habilidades de trabajo en equipo. RISTI - Revista Ibérica de Sistemas e Tecnologias de Informação, (E3), 71-83. https://doi.org/10.17013/risti.e3.71-83

Salen, K., \& Zimmerman, E. (2004a). Regras do Jogo: fundamentos do design de jogos: principais conceitos: volume 1. São Paulo: Edgard Blücher.

Salen, K., \& Zimmerman, E. (2004b). Regras do Jogo: fundamentos do design de jogos: regras: volume 2. São Paulo: Edgard Blücher.

Stake, R. E. (2010). Pesquisa qualitativa: estudando como as coisas funcionam. Porto Alegre: Penso.

Vaizey, E. (2015). Developing our knowledge and capability to secure cyber space. Em Developing Our Capability in Cyber Security: academic centres of excellence in cyber security research. London: UK Government.

Yin, R. K. (2014). Estudo de caso: planejamento e métodos. Porto Alegre: Bookman. 